\title{
Managing Services Marketing: Text and Readings.
}

John E. G. Bateson e K. Douglas Hoffman. 4. ed. Boston: Hardcover, 1998. 471p. ISBN 0-03-022519-1.

por Valter Vieira (UNIPAR)

Serviços é considerado um campo vultoso da área de Administração, particularmente em alguns países emergentes. A sua formação e amadurecimento cresceram bastante nas últimas três décadas. No Brasil, os serviços manipulam alguns dados interessantes do cenário econômico, como, por exemplo, é um setor que, por si só, emprega 57,2\% da mão-de-obra existente no mercado e representa 58,3\% de todo o Produto Interno Bruto (PIB), conforme o IBGE. Outro exemplo é que o campo de marketing de serviços está recebendo uma conotação muito importante em diferentes congressos acadêmicos ao redor do mundo, tais como uma área exclusiva no congresso da American Marketing Association. No Brasil, o mesmo já ocorre no Encontro Anual da Associação Nacional dos Programas de Pós-Graduação em Administração (ENANPAD).

Nós podemos definir o serviço como um produto intangível oferecido por uma firma, que pode ser visto, sentido ou experimentado, tais como cinema, transporte aéreo, hospitais, restaurantes. O serviço implica que não há um produto incluído, mas um único serviço. É importante salientar que os serviços não são produzidos, estocados e então vendidos, como ocorre com produtos; na realidade, os serviços são criados enquanto estão sendo vendidos. Em outras palavras, os serviços são uma variação especial dos produtos, o qual os consumidores podem, por eles mesmos, interagir e manipular.

Com base neste contexto, a Hardcover lançou o livro Managing Services Marketing: Text and Readings. Seus autores são nomes importantes e conhecidos neste campo ao redor do mundo. O primeiro autor, John Bateson, recebeu seu Ph.D. em Marketing pela Escola de Administração de Harvard e trabalha na firma de consultoria Gemini, em Londres. O segundo autor, K. Douglas Hoffman, também Ph.D., já escreveu dois livros na área e leciona a disciplina Marketing de Serviços na Universidade do Estado de Colorado, nos Estados Unidos. Esta sólida união levou a criação de uma grande obra, que analisamos nesta resenha.

Managing Services Marketing apresenta uma vantagem em seu conteúdo, devido ao fato de ser desmembrado em três grandes partes; ou seja, o livro é feito para fornecer ao leitor um bom encadeamento de informações e compreensão do texto. Elas são: (1) Construindo Blocos Básicos; (2) Dando Forma e 
Gerenciando uma Empresa de Serviços; e (3) Competindo com uma Empresa de Serviços.

Especificamente, a primeira parte, Construindo Blocos Básicos, compreende uma introdução e explicação sobre o que é uma empresa de serviço. Nela aspectos gerais são discutidos, com a finalidade de providenciar melhor introdução nas principais falhas existentes no gerenciamento de uma empresa normal e de uma empresa de serviços. Quatro capítulos sólidos proporcionam ao leitor a compreensão preliminar dessas diferenças, bem como daquelas existentes entre produtos e serviços. Os autores, como é comum em livros de marketing, apresentam um modelo do processo de compra do consumidor, não de produtos, mas de serviços.

No capítulo seguinte, Compreendendo o Consumidor de Serviços, é analisada a influência humana na escolha por um serviço. É importante salientar que o processo de consumo de um serviço é muito diferente do processo de compra e consumo de um simples produto. Assim, um caso significativo é apresentado pelos autores sobre isso: quando um consumidor está discutindo com o seu filho e com a sua esposa em um restaurante, um terceiro cliente próximo a eles presencia essa discussão e então não avalia se a comida, o serviço, o lugar, o atendimento, a velocidade do atendimento são boas; na realidade, ele vê e avalia o consumidor e sua péssima conduta com relação a sua família, o que acaba influenciando em seu grau de satisfação do serviço do restaurante. Em resumo, tratase de uma explicação do Modelo Servuction (Langeard et. al., 1981), utilizado em todo o livro para explicar melhor o que influencia no desempenho do serviço. Na continuação, em Administrando uma Operação de Serviços, é descrita a configuração do sistema de operação dos serviços como um típico ciclo de vida competitivo em serviços.

Na segunda e principal parte, intitulada Dando Forma a uma Empresa de Serviços, os autores inicialmente mostram as maneiras de dar forma a uma empresa de serviço. A seqüência desse processo de formação é: operação de serviços $\rightarrow$ construção do cenário dos serviços $\rightarrow$ os empregados da empresa $\rightarrow$ as estratégias de comunicação $\rightarrow$ a formação do preço.

Esta parte do livro apresenta toda a operação das empresas de serviços para o consumidor final. Por exemplo, a influência do cenário no processo de decisão, como o cheiro, o tipo de música (rápida/lenta), as luzes, as cores e outras características interessantes; os empregados e suas mudanças/trocas de papéis dentro da empresa como, por exemplo, o modo como o cliente é visto por eles. Um capítulo sobre estratégia de comunicação mostra a importância fundamental da maneira de construir e executar uma empresa de serviços orientada para o con- 
sumidor (consumer oriented). Os autores também comentam sobre a estratégia de formação de preço, que corresponde à configuração do preço com base em alguns aspectos diferentes, tais como tempo de serviço, lugar, natureza, entre outros (Guiltinan, 1987).

Na última parte são realizadas observações sobre um tópico significativo e emergente no mundo da Administração, a Satisfação do Consumidor com Serviços. A satisfação do consumidor, definida como uma avaliação da discrepância notada entre as expectativas prévias e o desempenho real de um produto ou serviço revisado depois de seu consumo (Marchetti e Prado, 2001), sua relação com qualidade de serviço (Parasuraman et al., 1988) e seus métodos de medição (Cronin Jr. e Taylor, 1992), é analisada e aí debatida de modos diferentes e isolados, fornecendo uma adequada explicação de como podemos compreender e depois mensurar eficientemente este constructo.

Competindo com uma Empresa de Serviços mostra o que as organizações devem fazer para competir eficientemente em um mercado cada vez mais competitivo. Na visão dos autores, as organizações devem possuir três características principais: vantagens competitivas genéricas, qualidade de serviços e conhecimento das necessidades dos clientes (orientada para o mercado). Esta parte é elaborada para ajudar as empresas de serviços a prestarem mais atenção nas necessidades de seus clientes.

Em síntese, este livro foi escrito especificamente para ajudar integrantes de programas de mestrado e doutorado na área de marketing. Ele não é recomendado para aqueles que estão à procura de uma leitura superficial nesse campo, devido à sua forte densidade. Vale salientar algumas de suas desvantagens, que, porém, não diminuem a sua elevada qualidade. A obra não apresenta um resumo no final de cada capítulo e tampouco algumas poucas questões de recapitulação, para consolidar o conteúdo para o leitor. Um CD-ROM interativo sobre o seu conteúdo é fornecido pela editora da Harvard Business School apenas nas primeiras edições, deixando outros leitores sem um importante complemento. Por outro lado, uma grande vantagem constitui seus dezessete artigos, retirados de periódicos conceituados tais como Journal of Marketing, Journal of Services Marketing, Journal of Consumer Research, Journal of Academy Marketing Science, e apresentados no final de cada capítulo, fornecendo excelente consistência ao texto.

Portanto Bateson e Hoffman nos presenteiam com uma ótima revisão em um importante campo da administração mercadológica, o Marketing de Serviços, e mostram que nós, como professores, consultores e executivos, ainda temos muito a fazer e contribuir para o seu desenvolvimento. Para aqueles que estão procu- 
rando se especializar neste campo, e buscam um bom livro para usar em seu curso de mestrado e doutorado, ou simplesmente para conhecer mais profundamente exemplos reais de serviços, esse clássico torna-se fortemente recomendável.

\section{ReferênCIAs Biblográficas}

CRONIN JR., J. J.;

TAYLOR, S. A.

Measuring service quality: a reexamination and extension. Journal of Marketing, n. 56, p. 5568, July 1992.

\section{GUILTINAN, J. P.}

The price bundling of services: a normative framework. Journal of Marketing, n. 51, p. 74-85, Apr. 1987.

LANGEARD, E. et al.

Marketing of services: new insights from consumer and managers. Cambridge, MA: Marketing Sciences Institute, 1981. p. 81-104.

MARCHETTI, R. Z.;

PRADO, P. H. M.

Um tour pelas medidas de satisfação do consumidor. Revista de Administração de Empresas, v. 41, n. 4, p. 56-67, out./dez. 2001.

PARASURAMAN, A. et al. SERVQUAL: a multiple-item scale for measuring consumer perceptions of service quality. Journal of Retailing, v. 1, n. 64, p. 12-40, 1988. 